\title{
Alternative Fuels Data Center
}
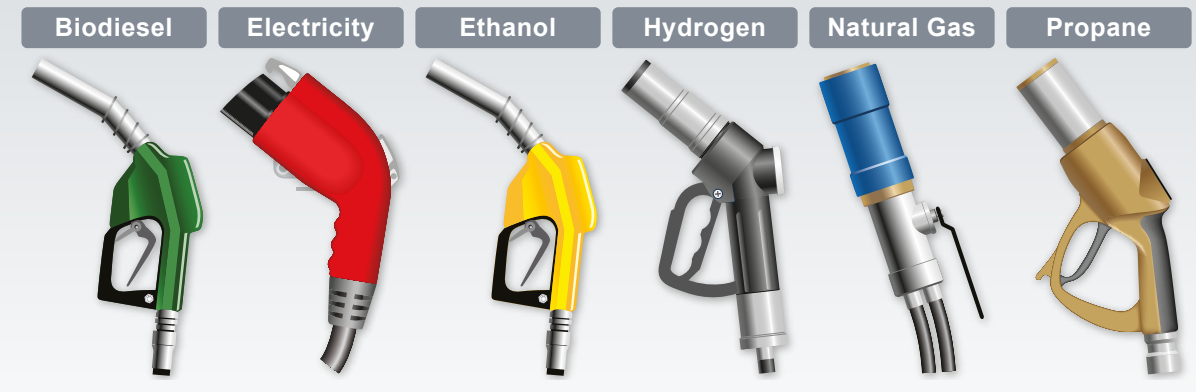

The premier information resource for alternative fuels and advanced vehicles.

The Alternative Fuels Data Center

(AFDC) provides a wealth of informa-

tion and data on alternative and

renewable fuels, advanced vehicles,

fuel-saving strategies, and emerging

transportation technologies. The site

features a number of interactive tools,

calculators, and mapping applications

to aid in the implementation of these

fuels, vehicles, and strategies. The

AFDC functions as a dynamic online

hub, enabling thousands of stake-

holders in the transportation system

to interact with one another.
The U.S. Department of Energy launched the AFDC in 1991 as a repository for alternative fuel vehicle performance data. Since that time, it has evolved to become an indispensable resource for fleets, fuel providers, policymakers, Clean Cities coalitions, and others working to improve efficiency, cut costs, and reduce emissions in transportation. Armed with the AFDC's data, information, and tools, these transportation stakeholders are increasing the use of domestic alternative fuels and advanced vehicle technologies every year, resulting in substantial benefits to the country's economy, energy security, and environment.

The AFDC provides extensive information about alternative and renewable fuels, including biodiesel, electricity,

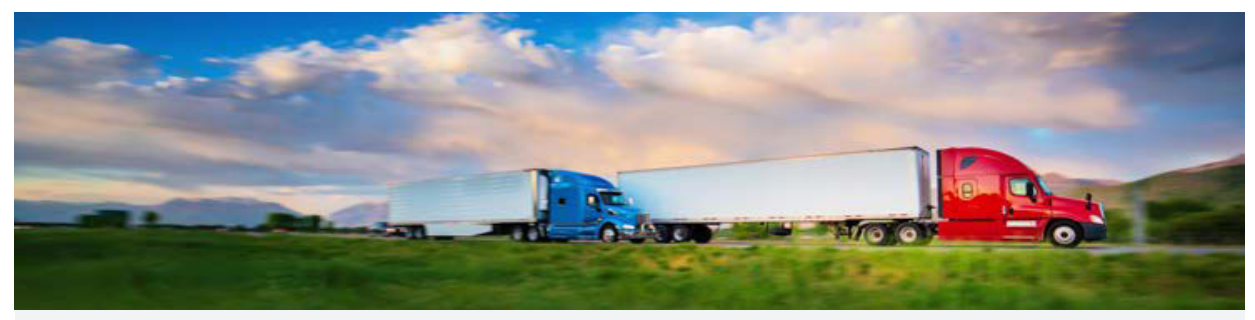

Real-World Case Studies

Thousands of fleet managers, business owners, state and local officials, and other transportation decision makers have already begun using alternative fuels, advanced vehicle technologies, and fuel-saving strategies in communities across the United States. The AFDC features hundereds of their stories in a library of case studies, searchable by geographic location, fuel or technology, application, and fleet type (afdc.energy.gov/case).

These case studies, offered in both written and video formats, serve as roadmaps for fleets and drivers, through which they can learn how others have overcome technical and financial barriers. Users can find real-life examples of delivery fleets, school districts, refuse collectors, and transit buses using innovative alternative fuel solutions, and police departments that have installed idle-reduction equipment in patrol vehicles. Photo from istock 982284558 ethanol, hydrogen, natural gas, propane, and other emerging fuels. Users can find out about fuel properties, production, distribution, prices, station locations, emissions benefits, and more. The site features information on the vehicles and engines that use these fuels and the corresponding fueling infrastructure. Fuel-saving strategies like idle reduction, fuel economy improvements, and efficient driving habits are also included on the AFDC.

The site's large suite of online tools and vast collection of vetted data empower fleets and drivers to identify the strategies and technologies that will best help them meet their environmental and energy goals in the most cost-efficient manner. Users can examine long-term trends, conduct cost estimates, project emissions benefits, compare multiple strategies, and identify fuels and technologies that are appropriate for their operational needs and geographic locations.

\section{Interactive Online Tools}

The AFDC features more than a dozen easy-to-use online tools (afdc.energy.gov/tools). These calculators, interactive maps, and data searches help fleets and drivers evaluate, select, and integrate alternative fuels and advanced vehicles as efficiently and costeffectively as possible.

\section{- Vehicle Cost Calculator}

(afdc.energy.gov/calc) allows users to enter information about driving habits to compare total cost of ownership and emissions for most vehicle models, including those that run on alternative fuels or electricity. 


\section{- CNG VICE Model 2.0}

(afdc.energy.gov/vice_model) helps fleet managers evaluate the return on investment (ROI) and payback period for compressed natural gas vehicles and infrastructure. Using fleet-specific data, the tool allows you to graphically chart key investment indicators, such as payback period, discounted cash flow, and annual emissions savings.

\section{- EVI-Pro Lite}

(afdc.energy.gov/evi-pro-lite) allows transportation planning officials to estimate how much electric vehicle charging a city or state might need to meet their goals. The model uses detailed data from personal vehicle travel patterns, electric vehicle attributes, and charging station characteristics. These data feed the tool's extensive simulations approach to estimate the quantity and type of charging infrastructure necessary to support regional adoption of electric vehicles.

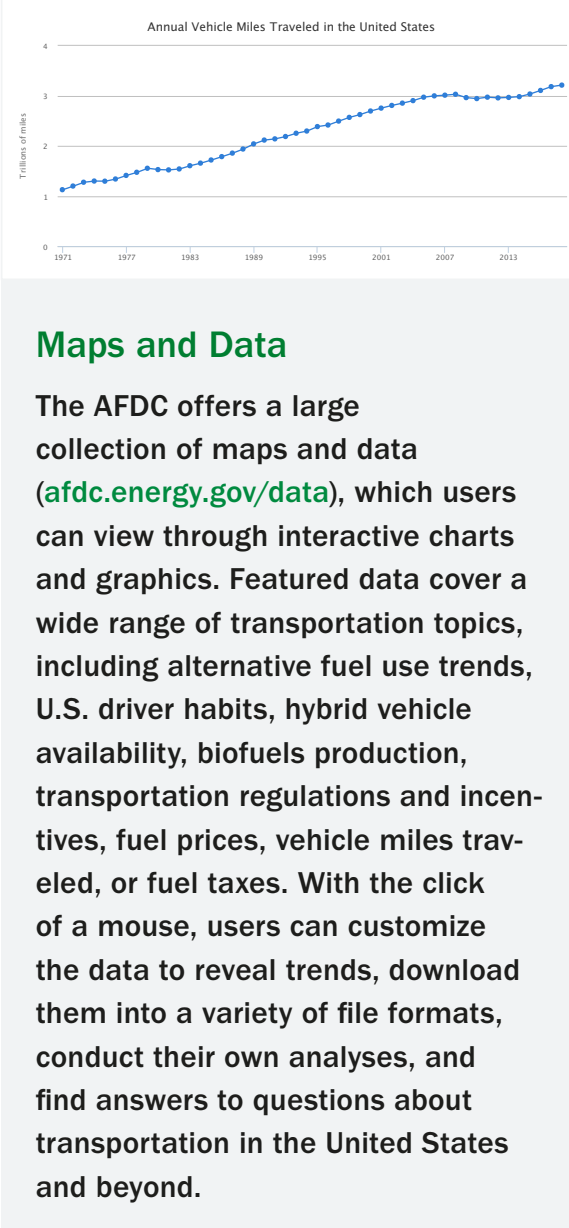

\section{Data Sharing}

Among its offerings, the AFDC also generates and provides robust datasets that help transportation stakeholders build applications, analyze information, and share tools with their constituents.

\section{- Application Programming Interfaces} (APIs): Several of the AFDC's datasets are available via an API and updated automatically on a continuous basis. These support analysis and tools developed by DOE and its National Laboratories, and are provided to public and private enterprises free of charge. This kind of data delivery is primarily used by organizations interested in building their own applications with the data.

- Data Downloads: AFDC data is also available for download. Data downloads are most often used by organizations wanting to build applications and upload the data into those applications, or by analysts doing research related to alternative fuels.

- Widgets: A number of AFDC tools are provided as widgets, which are snippets of code that let users embed AFDC content on their websites, blogs, or social networking sites. This allows users to include the content in their own websites without the expense of building their own tools.

\section{Laws and Incentives}

Applicable laws and incentives are important to consider before embarking on any advanced transportation project. The AFDC houses a comprehensive database of federal and state laws and incentives related to alternative fuels and vehicles, air quality, fuel efficiency, and other transportation topics (afdc.energy.gov/laws). Users can customize their queries with an advanced search function, as well as access summaries of recent federal actions, state updates, and a listing of key federal legislation. The site also includes examples of local laws and incentives.

\section{Technical Response Service}

800-254-6735 • technicalresponse@icf.com

Prepared by the National Renewable Energy Laboratory (NREL), a national laboratory of the U.S. Department of Energy, Office of Energy Efficiency and Renewable Energy; NREL is operated by the Alliance for Sustainable Energy, LLC.

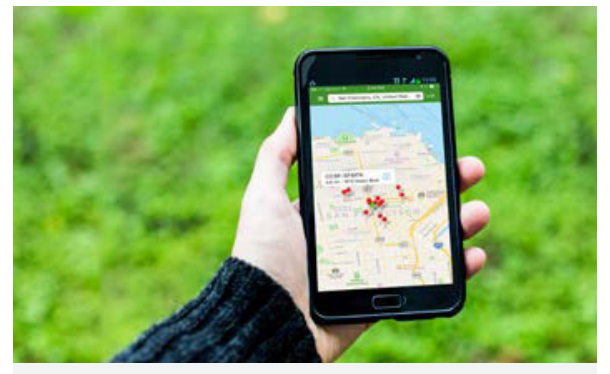

\section{Alternative Fueling Station Locator}

The Station Locator (afdc.energy.gov/stations) is among the AFDC's most popular tools. This interactive mapping application allows users to find stations that offer biodiesel, electric vehicle charging, ethanol, hydrogen, natural gas, and propane. Users can filter by fuel, find all stations near a given location, and map routes with stations identified along the way. The tool also provides station counts for individual states, the nation, and even stations in Canada. Users can easily download data, embed the Station Locator onto their own websites, and install the mobile apps to plan their alternative fuel trips.

The AFDC is a resource of the U.S. Department of Energy's Vehicle Technologies Office within the Office of Energy Efficiency and Renewable Energy. The website is administered by the National Renewable Energy Laboratory.

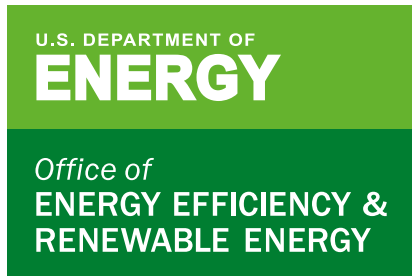

For more information, visit: afdc.energy.gov

DOE/GO-102019-5213 · December 2019 